\title{
Baccalaureate nurses Graduates and Undergraduates' Awareness Regarding Their Actual and Expected Role
}

\author{
${ }^{1}$ Sally S. Moustafa, ${ }^{2}$ Ehsan S. Solimn.${ }^{3}$ Hemat A. Mostafa \\ ${ }^{2}$ Lecturer of Nursing Administration, Faculty of Nursing, Benha University, ${ }^{3}$ Nursing \\ Administration Department, Faculty of Nursing, Ain-Shams University.
}

\begin{abstract}
: role clarity is important in the transition from student to professional role, as it prevents role overlap, role conflict, and role stress. So, the graduate baccalaureate nurses must be aware about demands, values, and responsibilities of their role after graduation. Purpose of the study was to identify baccalaureate nurses graduates and under graduate nurses' awareness regarding their actual and expected role at Benha University Hospitals .A descriptive design was used to achieve the purpose of the study. The study was conducted at two settings (Benha University Hospitals and Benha Faculty of Nursing). The sampling of the study was 560 of participants assign them into (260 of baccalaureate nurses and 300 of under graduates baccalaureate nurse). Baccalaureate nurse role self administered questionnaire was used by the researcher used for data collection. Results indicated that the majority of under graduate baccalaureate nurses $(92,3 \%)$ and graduate baccalaureate nurses $(97,7 \%)$ were aware of their expected and actual role. Conclusion it is concluded that the great majority of the two groups of the study subjects were aware of their actual and expected role. Recommendation every baccalaureate nurse should be aware about her role cooperation and collaboration between hospital staff and nursing faculty teaching staff was recommended.
\end{abstract}

Keywords: actual and expected role, graduate and under graduate baccalaureate nurses.

\section{Introduction:}

Baccalaureate program of nursing prepares baccalaureate nurses whose practice is based upon nursing science and related sciences and arts in order to promote, restore, and maintain the health of human beings (Smith, 2018). Also, it prepare them for working in health care environment with taking an active role in all facets of health care, they are expected to develop the nursing profession through their critical thinking and communication skill (American Association of colleges of nursing, 2017). Baccalaureate nursing graduates must manage an explosion of knowledge about health 


\section{Baccalaureate nurses Graduates and Undergraduates' Awareness Regarding \\ Their Actual and Expected Role}

and illness, always searching for evidence- based practice, while they navigate continuously new technologies. They must communicate effectively and collaborate with patients, families, groups, health care colleagues, and other interested parties, including the media, they must be critical and creative thinkers and able to apply the science of caring , often sharing in the most personal and private matters of life (Petterson, 2017). The transition period from student nurse to professional nurse practicing in hospital organization is turning point for the new graduate. They need new skills to be learned, understand professional relationship, and acquire autonomy in nursing practice (Jail, 2014). Graduate nurse when understand the perception of staff nurse role give information about the appropriateness of their perception and the change in system which affect the nurse role (Yahi, 2012). Role expectation can be clarified by using role models role, repletion, preceptors, mentors and interaction with professional refence group should occur ( Soliman, 2012).

\section{Purpose}

The purpose of the study is to identify baccalaureate nurses graduates and under graduates nurses' awareness regarding their actual and expected role at Benha University $\mathrm{H}$ hospitals.

\section{Research question}

1- What is the awareness of graduate baccalaureate nurse about their actual role?

2- What is the awareness of under graduate baccalaureate nurse about their actual role?

\section{Method}

\section{Research design:}

Descriptive research design was used to conduct this study.

\section{Research setting:}

The study was conducted at two settings, the first was Benha University Hospitals and the second was Benha Faculty of nursing

\section{Sampling :}

the study included all available graduate bacca-laureate nurses (260) nurses who working in different departments in hospital and under graduate nurses ( 300) who are studying in faculty of nursing during the time of data collection and agreed to participate in this study.

\section{Instruments:}

Data was collected through using one instrument: baccalaureate nurse role self-administered questionnaire. The instrument was developed by (Elsayed, 


\section{Baccalaureate nurses Graduates and Undergraduates' Awareness Regarding \\ Their Actual and Expected Role}

1999 and Fakhry, 2002). Reliability of instrument:

It was measured using Cronbach's alpha test to measure the internal consistency of the study tool it was 0,867.The instrument included two parts:

The first part: demographic data: it was used to assess graduate baccalaureate nurse's personal characteristics, this included (department in hospital, age, education, qualification, experiences year, marital status, residence, attending of training programs and number of nurses in unit). And undergraduate baccalaureate nurse's personal characteristics, this included (age, pre university education, marital status, residence, and attending of training programs).

The second part: baccalaureate nurses role: included (107) items that were grouped under the following five dimensions, nurse role:

1. Caregiver: included 60 items related to direct patient care, assessment, planning, implementation and evaluation of nursing care it is contained 6 parts. Role of care giver in internal department 10 , role of care giver in ICU15, role of care giver in surgical unit (before operation 4, during operation 3, after operation 6), role of care giver in emergency unit 12 , role of care giver in kidney dialysis 5, role of care giver in NICU6.

2. Manager included 17 items refer to managerial work in the clinical unit as sharing in patient rounds, work assignments, time management and coordination with other units.

3. Communicator: included 17 items related to verbal and nonverbal communication in dealing with patients, healthcare team and relatives, and recording activities as recording vital signs, medications, shift report and any nursing procedure.

4. Health educator included 8 items related to health education for the patient according to their diagnosis and healthcare team.

5. Researcher included 5 items refer to identify nursing problems in the clinical units, collect data about it, sharing in research committees, appraising research applicability and feasibility, and using the results in promoting nursing care.

\section{Scoring systems:}

\begin{tabular}{|l|l|}
\hline Score & Scoring items \\
\hline
\end{tabular}




\begin{tabular}{|l|l|}
\hline 2 & Agree \\
\hline 1 & Sometimes \\
\hline Zero & Disagree \\
\hline
\end{tabular}

Pilot study:

A pilot study was conducted on $10 \%$ of the study sample (30) from undergraduate baccalaureate nurses and (25) from graduate baccalaureate nurses, after the tool of data collection was prepared and before starting data collection to determine the applicability, clarity of the tool and determining the time needed for filling the questionnaire sheet .The time needed to fill the questionnaire sheet was about (15-20) minutes. No modifications were needed to be done after implementations of the pilot study were included in the total study subjects.

Validity of the study instrument: was done by five experts in the related field to check the relevancy, clarity, comprehend-siveness, and applicability of the tool of data collection. Jury experts involved three assistant professors of nursing administration from faculty of nursing Ain -Shames University and two assistant professor of nursing administration from faculty of nursing Tanta University. Experts' According to expert's opinions, minor modifications were done such as remove some items as (applying gastric tube, applying urine catheter) and the final form of the questionnaire was prepared.

\section{Ethical considerations}

d-The time needed to complete questionnaire sheet (13) minutes. The appropriate time of data collection was according to type of work and work load of each department, sometimes it was in the middle of the shift and other time before the end of the shift.

\section{Informal consent}

The respondent rights will be protected by ensuring voluntary participation, so the informed consent will be obtained by explaining purpose, nature time of conducting the study, potential benefits of the study, how data will be collected, no invasive procedure, expected outcomes and the respondent rights to withdrawing from the research study at any time in case of violation of his rights.

\section{Procedure}

\section{1-}

\section{Official approval:}

An official permission was issued from dean of the faculty of nursing to the director of Benha University Hospital to obtain the approval for data 


\section{Baccalaureate nurses Graduates and Undergraduates' Awareness Regarding \\ Their Actual and Expected Role}

collection, the objectives and the nature of the study were explained and then it was possible to carry out the study with minimum resistance.

\section{2-}

\section{mplementation phase}

a. A-Each graduate and undergraduate baccalaureate nurse was interviewed after explaining the purpose of the study and getting agreement of them to participant in the research.

b. b- Data has been collected from graduate and under graduate baccalaureate nurse in above mentioned study at Benha Faculty of Nursing and Benha University Hospital.

B. Collection of data took three months beginning of July / 2017 to the end of September /2017, the researcher applied interview for study sample for three days per week.

C. The time needed to complete questionnaire sheet13 minutes. The appropriate time of data collection was according to type of work and work load of each department, sometimes it was in the middle of the shift and other time before the end of the shift.

\section{Informal consent}

The respondent rights will be protected by ensuring voluntary participation, so the informed consent will be obtained by explaining purpose, nature time of conducting the study, potential benefits of the study, how data will be collected, no invasive procedure, expected outcomes and the respondent rights to withdrawing from the research study at any time in case of violation of his rights.

\section{Anonymity and confidentiality}

The respondents will be assured that the data will be treated as strictly confidential: further-rmore, the respondent anonymity will be maintained as they will not require mentioning their names.

\section{Scientific honesty}

To ensure scientific honesty, the researcher used bucketing and intuiting to avoid bias.

\section{Statistical analysis}

Data were verified prior to entry into computer; statistical package for social science (SPSS, version twenty) was used for that purpose, followed by data analysis and tabulation. Level of significance for all statistical tests Which have been done was considered at the 5\% level, a 


\section{Baccalaureate nurses Graduates and Undergraduates' Awareness Regarding \\ Their Actual and Expected Role}

significance level value was while $(\mathrm{P}$ - value) $>0.05$ it indicates non considered when (P- value) $<0.05 \quad$ significance difference in the result.

\section{Results}

Table (1): Distribution of studied graduate baccalaureate nurses regarding their sociodemographic characteristics $(n=260)$.

\begin{tabular}{|c|c|c|}
\hline Personnel characteristics & Frequency & $\%$ \\
\hline \multicolumn{3}{|l|}{ Age in years } \\
\hline $22-30$ & 106 & 39.8 \\
\hline $31-40$ & 137 & 51.5 \\
\hline $40-50$ & 23 & 8.6 \\
\hline Mean \pm SD & $29.67 \pm 7.39$ & \\
\hline \multicolumn{3}{|l|}{ Job } \\
\hline Staff nurse & 248 & 93.2 \\
\hline Head nurse & 18 & 6.8 \\
\hline \multicolumn{3}{|l|}{ Educational qualification } \\
\hline Nursing bachelor & 16 & 6.0 \\
\hline Diploma in nursing & 219 & 82.3 \\
\hline Master degree in nursing & 31 & 11.7 \\
\hline \multicolumn{3}{|l|}{ Residence } \\
\hline Rural & 128 & 48.1 \\
\hline Urban & 138 & 51.9 \\
\hline \multicolumn{3}{|l|}{ Years of experience } \\
\hline Less than 5 years & 57 & 21.4 \\
\hline $5<10$ years & 79 & 29.7 \\
\hline $10<15$ years & 82 & 30.8 \\
\hline 15 years & 48 & 18.0 \\
\hline
\end{tabular}




\section{Baccalaureate nurses Graduates and Undergraduates' Awareness Regarding Their Actual and Expected Role}

Table (2): Clarifies that the majority of undergraduate baccalaureate nurses age ranged between (20-21) years old, also three quarter of undergraduate baccalaureate nurses (70. 7\%) had general type of secondary education to enter the faculty as regarding their marital status majority $(82.7 \%)$ of them were single, as their residence one quarter $(66.0 \%)$ were in urban and more than half $(56 \%)$ had a training program.

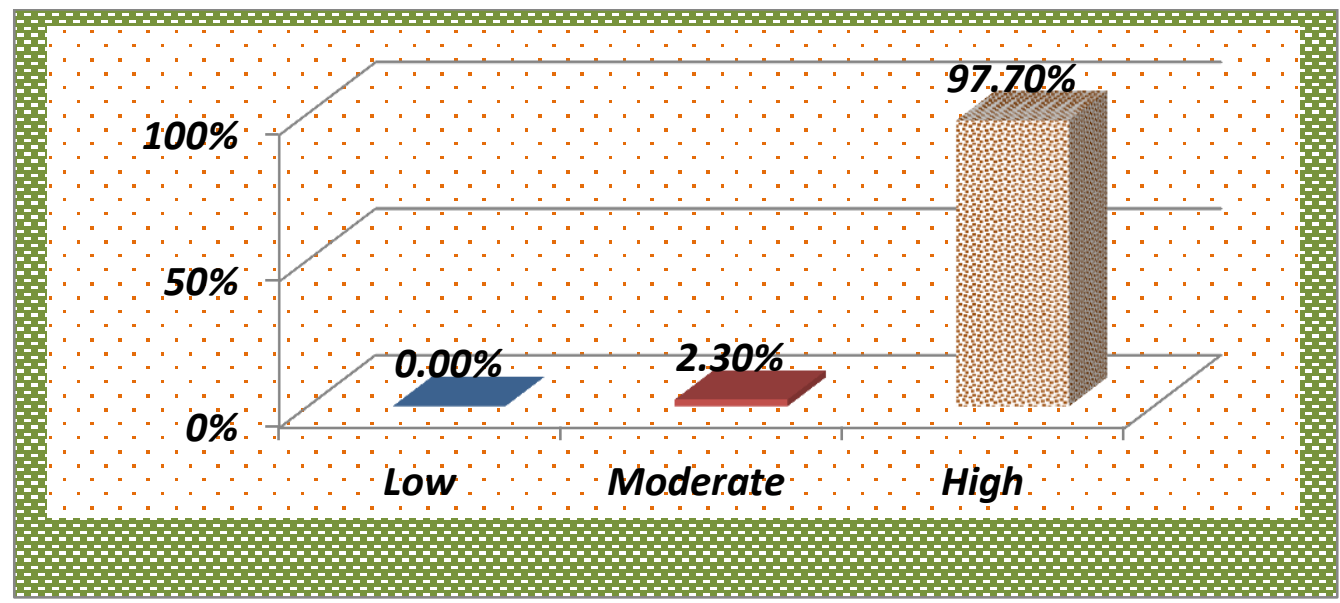

Figure (1): Distribution of studied graduate baccalaureate nurses awareness regarding their actual role.

Figure (1): Clearly illustrated that the majority of graduate baccalaureate nurses have high awareness $(97.70 \%)$ of their actual role.

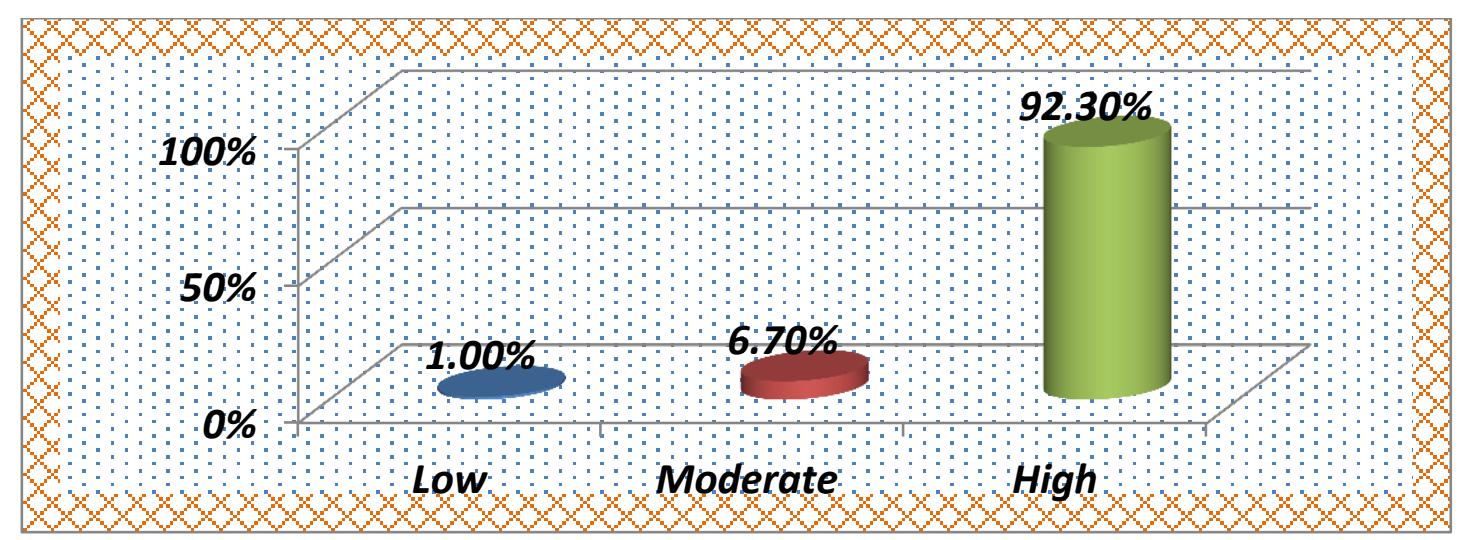

Figure (2): Distribution of studied undergraduate baccalaureate nurses awareness regarding their expected role after graduation.

Figure (2): Clearly illustrates that the majority of undergraduate baccalaureate nurses have higher awareness $(92.30 \%)$ about their expected role. 


\section{Baccalaureate nurses Graduates and Undergraduates' Awareness Regarding Their Actual and Expected Role}

Table (3):level of awareness of graduate and under graduate baccalaureate nurses mean score regarding their actual and expected role $(\mathrm{n} 1=260 \& \mathrm{n} 2=300)$.

\begin{tabular}{|c|c|c|c|c|}
\hline Role of nurses & $\begin{array}{c}\text { Awareness of } \\
\text { undergraduate } \\
\text { baccalaureate } \\
\text { nurse }\end{array}$ & $\begin{array}{c}\text { Awareness of } \\
\text { graduate } \\
\text { baccalaureate nurse }\end{array}$ & $\begin{array}{l}\text { Independent } t \\
\text { test }\end{array}$ & $P$ value \\
\hline & Mean \pm SD & Mean \pm SD & & \\
\hline $\begin{array}{l}\text { Nursing activities related to their role as a } \\
\text { caregiver in internal department }\end{array}$ & $17.6933 \pm 2.09617$ & $18.2744 \pm 2.32863$ & 3.10 & $<0.05 *$ \\
\hline Role of a caregiver in ICU unit & $25.2800 \pm 5.13447$ & $28.6429 \pm 2.53062$ & 10.05 & $<0.001 * *$ \\
\hline $\begin{array}{l}\text { Role of a caregiver in surgical unit } \\
\text { (before, during and after surgery) }\end{array}$ & $24.4767 \pm 2.30082$ & $24.5338 \pm 2.99067$ & 0.252 & $>0.05$ \\
\hline $\begin{array}{l}\text { Role of health care provider in emergency } \\
\text { unit }\end{array}$ & $22.6133 \pm 2.26146$ & $23.1880 \pm 1.82292$ & 3.34 & $<0.001 * *$ \\
\hline Role of a caregiver in kidney dialysis unit & $9.3167 \pm 1.41766$ & $9.5752 \pm .92143$ & 2.59 & $<0.05^{*}$ \\
\hline Role of a caregiver in incubator unit & $11.0767 \pm 1.84449$ & $11.2782 \pm 1.47099$ & 1.44 & $>0.05$ \\
\hline Role of a manager nurse & $30.7767 \pm 4.66756$ & $32.5000 \pm 3.12778$ & 5.21 & $<0.001 * *$ \\
\hline Role of a communicator nurse & $29.0267 \pm 4.20932$ & $30.6429 \pm 2.81041$ & 5.42 & $<0.001 * *$ \\
\hline Role of health care health educator & $14.6233 \pm 2.32223$ & $15.0263 \pm 1.80232$ & 2.31 & $<0.05^{*}$ \\
\hline Role researcher nurse & $9.1733 \pm 1.50026$ & $9.0677 \pm 1.27794$ & 0.905 & $>0.05$ \\
\hline Total awareness & $194.056 \pm 16.01045$ & $202.7293 \pm 11.92848$ & 7.35 & $<0.001 * *$ \\
\hline
\end{tabular}

Significant at $\mathrm{p}<0,05$

Table (3): Shows the mean score of graduate and under graduate baccalaureate nurses awareness regarding to nursing role. The mean score of graduate baccalaureate nurses awareness is higher than the mean score of under graduate baccalaureate nurses awareness regarding to the nursing role as a care giver in (internal unit, ICU units, surgical unit, emergency units, kidney unit and incubator care unit) and as a manager, as a communicator and as a researcher. Also table (25) points to there were significance difference at $\mathrm{p}<0, \quad 05$ among the study subjects in all items except (role of a care giver in surgical unit, role of a care giver in incubator and role of a researcher). 


\section{Baccalaureate nurses Graduates and Undergraduates' Awareness Regarding Their Actual and Expected Role}

Table (4): Total level of awareness of graduate and under graduate baccalaureate. Nurses regarding to their actual and expected role nurses (n1=260 \&n2=300).

\begin{tabular}{|c|c|c|c|c|c|c|}
\hline \multirow[t]{2}{*}{$\begin{array}{l}\text { Total awareness } \\
\text { score }\end{array}$} & \multicolumn{2}{|c|}{$\begin{array}{c}\text { Awareness of } \\
\text { undergraduate } \\
\text { baccalaureate nurses }\end{array}$} & \multicolumn{2}{|c|}{$\begin{array}{l}\text { Awareness of graduate } \\
\text { baccalaureate nurses }\end{array}$} & \multirow{2}{*}{$\begin{array}{l}\text { Chi } \\
\text { square } \\
\text { test }\end{array}$} & \multirow[t]{2}{*}{$P$ value } \\
\hline & No & $\%$ & No & $\%$ & & \\
\hline Low & 3 & $1.0 \%$ & 0 & $0.0 \%$ & \multirow{3}{*}{9.06} & \multirow{3}{*}{$<0.05^{*}$} \\
\hline Moderate & 20 & $6.7 \%$ & 6 & $2.3 \%$ & & \\
\hline High & 277 & $92.3 \%$ & 260 & $97.7 \%$ & & \\
\hline
\end{tabular}

Table (4): Shows comparison between graduate and undergraduate baccalaureate nurses awareness regarding the role of baccalaureate nurse as reported by study subjects. It can be observed that there were highest percentage awareness $(97,7 \%)$ were reported by graduate baccalaureate nurses. On the other hand the lowest percentage awareness (92, 3\%) was reported by under graduate baccalaureate nurses. Also table (26) points to there were significance difference atp $<0,05$ among study subjects.

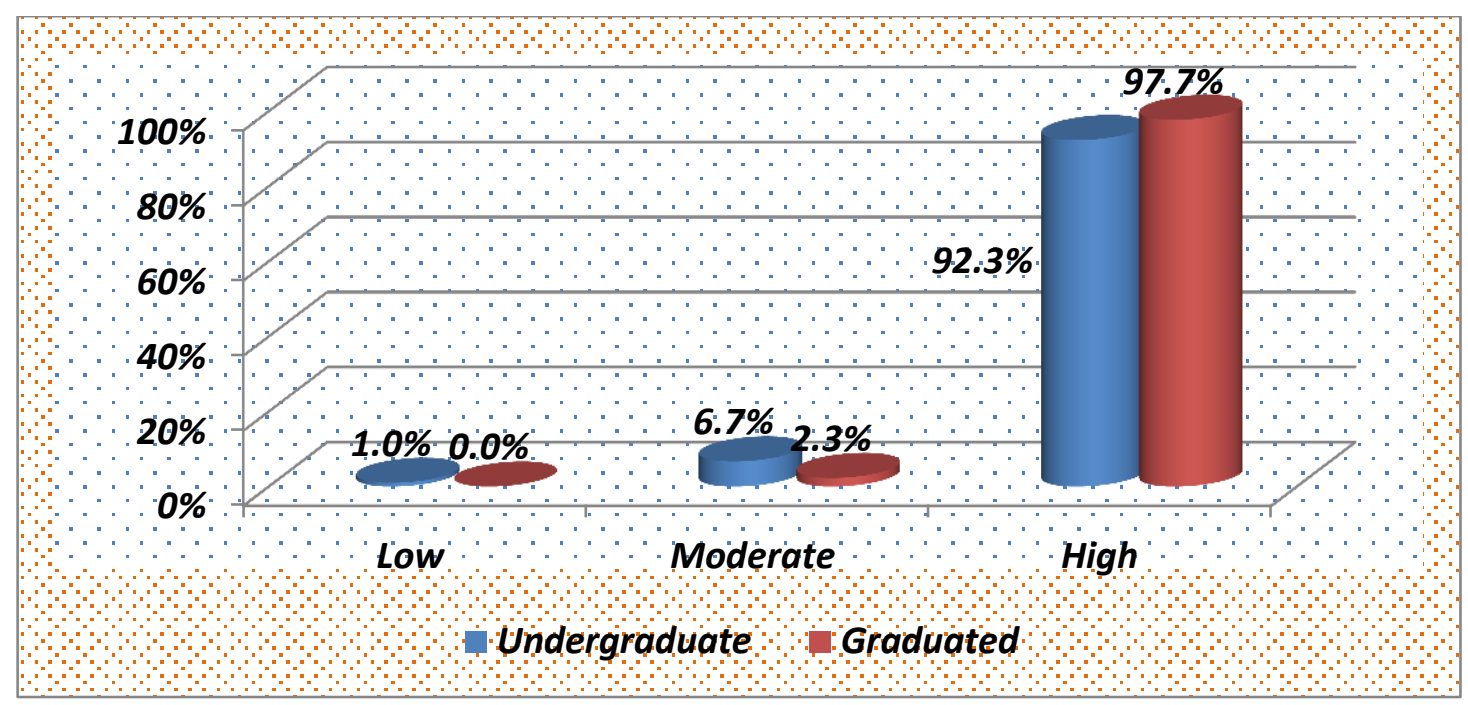

Figure (3): Distribution of studied graduate and undergraduate baccalaureate nurses awareness regarding their actual and expected role.

Figure (3): Clearly illustrates that graduate baccalaureate nurses have high awareness about their actual role $(97.7 \%)$ than undergraduate baccalaureate nurses awareness about their expected role $(92.3 \%)$. 


\section{Baccalaureate nurses Graduates and Undergraduates' Awareness Regarding \\ Their Actual and Expected Role}

\section{Discussion}

The finding of the present study revealed that majority of graduate baccalaureate nurses had an overall agreement upon nurse's role as caregiver based in nursing process (assessment, planning, implementation and evaluation) of nursing care. Which reflects the importance of this role in the awareness of graduate baccalaureate nurses? This finding is consistent with Potter and Perry (2017) as they reported that the flexible structure of nursing process provides a framework enabling nurses in all health care Settings to identify and meet patient needs these sequential steps provide a systematic format that ensures continuity of patient care and maintenance of professional standards while assisting patients to regain and maintain, promote health. Also, the majority of graduate baccalaureate nurses show a high percentage of agreement about nursing role in the technical procedure.

Regarding the graduate and under graduate baccalaureate nurses awareness about nurse role as a manager shows that the majority of them agreed about all items especially planning work time to provide Necessary nursing care and record

nursing care in the patient file. This is in accordance with Slaman (2012) who found high agreements in all items. Potter and Perry (2016) emphasized that the nurse should manage patient care and the delivery of specific nursing services within a health care agency. Therefore, the functions of a nurse manager include budgeting, staffing, strategic planning of services, employees' evaluation, and employees' development.

Regarding the graduate and under graduate baccalaureate nurses awareness about nurse role as communicator, results of the present study demonstrated the majority of nurses reported highest agreement about all items (verbal and non-verbal communication) especially in recording drug after administration. These previous results were confirmed by Hassan (2014) who reported that most of nurse teacher reported agreement about all items. This may be because Effective communication is an important aspect of patient care, which improves nurse -patient relationship and has a profound effect on the patient's perceptions of healthcare quality and treatment outcomes.Norouzinia et al., (2016). 


\section{Baccalaureate nurses Graduates and Undergraduates' Awareness Regarding \\ Their Actual and Expected Role}

This in congruence with Timby and Smith, (2003) who mentioned that nurses must document all nursing actions, observations, and client responses in a permanent record. This record of nursing actions should be a mirror image of the written plan.

Regarding the graduate and under graduate baccalaureate nurses awareness about nurse role as a health care educator, results of the present study demonstrate the majority of the graduate baccalaureate nurses awareness about nurse role as health care educator especially training of new nurses in the department and identify the training needs of nurses. This could be attributed to recent emphasis on active patient and family role in selfcare activities. Through this role the baccalaureate nurse can help patient and families to develop the self-care abilities that will enable them to maximize their functioning and quality of life. These previous results were confirmed by Hassan (2014) who reported that most of nurse teacher reported agreement about all items. In the same line Chaghar et al., (2017) reported that Training is an essential factor contributing to greater efficiency of the staff and organizations. It's a vital investment that will lead to internal promotion, staff developing and success of organizational plans, training is important in achieving productivity and nurse retention through providing career development and job satisfaction in the long run. Concerning nurse's role as a researcher, the findings of the present study showed that the majority of them agree about all items especially share in attendance scientific program either in units or community .The finding could be attributed to the realization of the nursing intern students of the importance of evidence-based practice of nursing, which is given emphasis recently. This would certainly foster the role of the nurse as a researcher. The finding is in agreement with Solamen (2012) who found that the majority of nursing intern students had a high perception of the role of the nurse as a researcher.

This study showed that There were high significant at $\mathrm{p}<0.05$ between graduate and undergraduate baccalaureate nurses awareness mean score regarding their actual and expected role. Mean score of graduate baccalaureate nurse is higher in caregiver in (internal department, in ICU, in emergency, in surgical department, in kidney unit, incubator), 


\section{Baccalaureate nurses Graduates and Undergraduates' Awareness Regarding \\ Their Actual and Expected Role}

manager role and health care educator role. Also total mean score of awareness of graduate baccalaureate nurse is higher than awareness of under graduate nurse. Also there was significance difference at $\mathrm{p}=0.05$ in distribution awareness of graduate and undergraduate nurses regarding their actual and expected role. The awareness of graduate nurses regarding their actual role is higher than awareness of undergraduate nurses regarding their expected role. This could be attributed to years of experiences of graduate nurses that they working in real filed and training programs that identified there actual role results agree with Hassan,(2014)who reported that the perception of nurse teacher of nurse role is higher than perception of nursing students of nurse role

\section{Conclusion}

The majority of graduate and undergraduate baccalaureate nurses had an overall awareness of their actual and expected role as a caregiver, manager, communicator, educator and researcher. The mean score of graduate baccalaureate nurses awareness of their actual role is higher than undergraduate nurses awareness of their expected role as a care giver in(internal unit, ICU unit, surgical departments, emergency departents, kidney unit and incubator care units), communicator role, researcher role and as a manager role. The awareness of graduate baccalaureate nurses about their actual role is higher than awareness of undergraduate baccalaureate nurses about their expected role and there was a significant difference between graduate and undergraduate total awareness mean score regarding their actual and expected role.

\section{Recommendation}

\section{For the faculty of nursing:}

- Collaboration should be promoted to connect gradu-ate baccalaureate nurse to the real world of nursing through support, empow-erment, and motivation in clinical area with follow up for their role performance.

- Preparation and selection of nursing preceptors are vital for assisting undergraduate baccalaureate nurse in role transition from student to professional nurse.

- The curriculum of baccalau-reate program must be based on their 


\section{Baccalaureate nurses Graduates and Undergraduates' Awareness Regarding \\ Their Actual and Expected Role}

needs assessment with special concerns for clarification of their role during preparation of new graduate programs, its goals and objectives should be clear.

- Providing good training programs for undergraduate baccalaureate nurses to clarify demands of the role.

- Provide feedback to the undergraduate baccalaureate nurses to assess weaken and strong points of performance and enhance their performance.

\section{For hospital management l:}

- Assess the clinical learning needs of new nurses periodically and develop a training program for them to the challenges facing in the real work environment.

- Creating healthy training environment is highly needed for new nurses during role transitions.

- Periodically update and develop job descriptions for the different nursing positions.

- Enhance mutual respect and effective communication betw-een graduate and undergraduate nurses and other hospital staff.
- Hospital nursing staff should be act as role models for undergraduate nurses.

- Hospital nursing standard for nursing procedures should be available to undergraduate baccalaureate nurses to implement their role effectively and efficiently.

\section{For further researchers:}

- Further studies suggest measuring the quality of baccalaureate nurses performance of their role.

\section{References}

American Association of colleges of nursing programs. (2017): Baccalaureate nursing programs. Http: // www.Aacn. Nche. Edu/ education- resources? Bsn-article, $\underline{1-4 .}$

El sayed . (2010): Baccalaureate students nurse perception of staff nurse role at high institute of nursing Cairo University, unpublished master thesis. 10-15.

Fakhry, S.,\& Bolice. (2008): Nurse interns role, leaders and interns perspectives, un published thesis, Ain Shams University, 16-44

Hassan, R. (2014): Graduate nurse role as perceived by students versus nurse teacher at technical institute. 


\section{Baccalaureate nurses Graduates and Undergraduates' Awareness Regarding \\ Their Actual and Expected Role}

Master thesis, un published, Ain Shams Unive-rsity. 1-16.

Jail., A. (2014): Factors affecting nurses coping with transition, global journal of health science, v6 (6),pp1-6.

Petterson, L.(2017): The experiences of transition by baccalaureate nursing graduates. Doctor thesis, Grand Fork University, published thesis, 60-65.

Smith, Y.(2018): Role of nurse. News medical life sciences. V (5), 1-4.

Smith, N., \&Timby, B. (2003): Introducatiory medical surgical nursing. $9^{\text {th }}$ edition, London, Lippincott Williamas and Wilkins, 21-22.

Soliman, E., S., (2012): Nursing intern students role as perceived by themselves and their super-visiors, un published, mas-terthesis, Benha University.

Yahia., M., ( 2012): Expectation related to head nurses roles as expressed by nursing professionals and it is relation to their performance, un published, master thesis, Cairo University, pp, 7075. 